\title{
The effect of apoE genotype and sex on ApoE plasma concentration is determined by dietary fat in healthy subjects
}

\author{
Juan Antonio Moreno ${ }^{1}$, Francisco Pérez-Jiménez ${ }^{1}$, Rafael Moreno-Luna ${ }^{1}$, Pablo Pérez-Martínez ${ }^{1}$, \\ Francisco Fuentes-Jiménez ${ }^{1}$, Carmen Marín ${ }^{1}$, Henri Portugal ${ }^{2}$, Denis Lairon ${ }^{2}$ and José López-Miranda ${ }^{1}$. \\ ${ }^{1}$ Lipids and Atherosclerosis Research Unit, Hospital Universitario Reina Sofía, Avda Menéndez Pidal, s/n. 14004, Córdoba, Spain \\ ${ }^{2}$ UMR 476-INSERM/1260-INRA, University and Central Analytical Laboratory, Ste Marguerite University Hospital, Marseille, \\ France
}

(Received 7 April 2008 - Revised 22 August 2008 - Accepted 26 September 2008 - First published online 24 November 2008)

The interindividual variation in ApoE plasma concentration is considerable, mainly determined by apoE genotype and sex. However, a large amount of variability remains unexplained by these factors. We have evaluated whether the quantity and quality of dietary fat interacts with the apoE genotype and sex modifying ApoE plasma levels in young healthy subjects. Eighty-four volunteers (sixty-six apoE3/3, eight apoE4/3 and ten apoE3/2) were subjected to three dietary periods, each lasting 4 weeks. The first was a SFA-enriched diet (38\% fat and $20 \%$ SFA), which was followed by a carbohydrate (CHO)-rich diet $30 \%$ fat, $<10 \%$ SFA and $55 \%$ carbohydrate) or a MUFA-rich diet (38\% fat and $22 \%$ MUFA) following a randomised crossover design. apoE2 carriers have the highest ApoE levels, whereas apoE4 individuals show the lowest concentration after the SFA, CHO and MUFA diets. Women had significantly higher ApoE concentration than men only after the consumption of the SFA diet. The SFA diet increased the ApoE plasma concentration when compared with the CHO- and MUFA-rich diets in women, but not in men. In women, but not in men, the shift from the SFA- to CHO- or MUFA-rich diets significantly decreased the ApoE concentration in apoE3/2 and apoE3/3 subjects, whereas no differences were observed in women with the apoE4/3 genotype. Sex and $a p o E$ genotype determine ApoE plasma levels; however, this effect is dependent on dietary fat.

apoE genotype: Diet: Sex: ApoE concentration

ApoE is a structural component of several lipoproteins and plays an important role in lipid metabolism through both promoting efficient uptake of TAG-rich lipoproteins from the circulation ${ }^{(1,2)}$ and taking part in the cellular cholesterol efflux and reverse cholesterol transport ${ }^{(3)}$. This apoE presents three major isoforms (ApoE2, ApoE3 and ApoE4) that modulate plasma lipid levels and have been implicated in CHD. The apoE4 allele is associated with increased risk of CHD, higher total and LDL-cholesterol and lower ApoE concentrations, whereas the apoE2 allele presents the opposite effects ${ }^{(4,5)}$. Nevertheless, the apoE polymorphism is insufficient to explain the development of $\mathrm{CHD}$, and several works give increasing evidence that serum concentration of ApoE, by itself, could play an independent role in this process ${ }^{(6-9)}$. Thus, circulating ApoE concentration appears to be altered in hyperlipidaemia $^{(10-13)}$, and case-control studies show that ApoE levels might be a cardiovascular risk factor ${ }^{(14-19)}$.

The total interindividual variation in serum ApoE concentration is considerable in Caucasian populations $(25-32 \%)^{(20)}$. It has been reported that up to $30 \%$ of the total variability in the ApoE concentration can be attributed to the apoE polymorphism ${ }^{(20,21)}$; however, a large amount of variability remains unexplained by this genetic factor, suggesting that other genetic or environmental components, such as sex or diet, are major determinants of its concentration. In agreement with this hypothesis, previous data have shown that cholesterol, fatty acids and oestrogens modulate liver ApoE secretion ${ }^{(22)}$. Furthermore, it has been demonstrated in both human ${ }^{(23,24)}$ and animal studies ${ }^{(13,25)}$ that a diet high in saturated fat and cholesterol leads to elevations in the ApoE plasma levels. These observations suggest that changes in the circulating levels of ApoE may be an important consequence of dietary habits. However, to our knowledge, no previous studies have compared the effect of both the quantity and quality of dietary fat on the ApoE plasma concentration. On the other hand, studies assessing associations between sex and ApoE concentration have shown contradictory results. Indeed, in some studies, it has been demonstrated that ApoE plasma levels were higher in women ${ }^{(26-28)}$, whereas others reported higher ApoE plasma concentration in men ${ }^{(29)}$ or even no difference was observed between men and women ${ }^{(30)}$. Therefore, the objective of the present study was to analyse whether the quantity and quality of dietary fat interacts with the $a p o E$ genotype or sex determining ApoE plasma levels in young healthy subjects.

Abbreviation: $\mathrm{CHO}$, carbohydrate.

* Corresponding author: José López-Miranda, fax +34957 218250, email jlopezmir@uco.es 


\section{Materials and methods}

Human subjects

A group of eighty-four subjects (eight apoE4/3, sixty-six apoE3/3, ten apoE3/2), including both men ( $n 56$; four $4 / 3$, forty-six $3 / 3$ and six $3 / 2$ ) and women ( $n$ 28; four 4/3, twenty $3 / 3$ and four $3 / 2$ ), were recruited from among students at the University of Cordoba. The subjects had a mean age of 21.55 years (SD 0.40). Informed consent was obtained from all participants. All subjects underwent a comprehensive medical history, physical examination and clinical chemistry analysis before enrolment. The subjects showed no evidence of any chronic disease (hepatic, renal, thyroid or cardiac dysfunction), obesity or unusually high levels of physical activity (e.g. sports training). None of the subjects had a family history of premature coronary artery disease, or had taken medications or vitamin supplements in the 6 months before the study. Physical activity and diet, including alcohol consumption, were recorded in a personal $\log$ for 1 week and the data were used to calculate individual energy requirements. Mean BMI was $22.86 \mathrm{~kg} / \mathrm{m}^{2}$ (SD 0.28 ) at the onset of the study and remained constant throughout the experimental period. The subjects were encouraged to maintain their regular physical activity and lifestyle, and were asked to record in a diary any event that could affect the outcome of the study, such as stress, change in smoking habits and alcohol consumption or intake of foods not included in the experiment design. No changes in lifestyle were observed at the end of the study. The study protocol was approved by the Human Investigation Review Committee at the Reina Sofia University Hospital.

\section{Diets}

The study design included an initial 28-day period during which all subjects consumed a SFA-rich diet, with $15 \%$ protein, $47 \%$ carbohydrate and $38 \%$ fat $(20 \%$ SFA, $12 \%$ MUFA and $6 \%$ PUFA). After this period, volunteers were randomly assigned to one of two diet sequences. Forty-two subjects received a MUFA-rich diet containing $15 \%$ protein, $47 \%$ carbohydrates and $38 \%$ fat $(<10 \%$ SFA, 6\% PUFA and $22 \%$ MUFA) for $28 \mathrm{~d}$. This diet was followed for $28 \mathrm{~d}$ by the consumption of a carbohydrate $(\mathrm{CHO})$-rich diet containing $15 \%$ protein, $55 \%$ carbohydrates and $<30 \%$ fat $(<10 \%$ SFA, $6 \%$ PUFA and $12 \%$ MUFA). The other forty-two subjects consumed the $\mathrm{CHO}$ diet before the MUFA diet. The cholesterol content remained constant (under $300 \mathrm{mg} / \mathrm{d}$ ) during the three periods. Eighty per cent of the MUFA diet was provided by virgin olive oil, which was used for cooking, salad dressing and as a spread. Carbohydrate intake of the $\mathrm{CHO}$ diet was based on the consumption of biscuits, jam and bread. Butter and palm oil were used during the SFA dietary period.

The composition of the experimental diets was calculated using the US Department of Agriculture ${ }^{(31)}$ food tables and Spanish food composition tables for local foodstuffs ${ }^{(32)}$. All meals were prepared in the hospital kitchen and were supervised by a dietitian. Lunch and dinner were eaten in the hospital dining room, whereas breakfast and an afternoon snack were eaten in the medical school cafeteria. Fourteen menus were prepared with regular solid foods and rotated during the experimental period. Duplicate samples from each menu were collected, homogenised and stored at $-70^{\circ} \mathrm{C}$. Protein, fat and carbohydrate contents of the diet were analysed by standard methods ${ }^{(33)}$. Dietary compliance was verified by analysing the fatty acids in LDL-cholesteryl esters at the end of each dietary period ${ }^{(34)}$. The study took place from January to March to minimise seasonal effects and academic stress.

\section{Lipid analysis and biochemical determinations}

Venous blood samples were collected into EDTA-containing $(1 \mathrm{~g} / \mathrm{l})$ tubes from all subjects after a $12 \mathrm{~h}$ overnight fast at the beginning of the study and at the end of each dietary period. Plasma was obtained by low-speed centrifugation for $15 \mathrm{~min}$ at $4^{\circ} \mathrm{C}$ within $1 \mathrm{~h}$ of venepuncture. To reduce interassay variation, plasma was stored at $-80^{\circ} \mathrm{C}$ and analysed at the end of the study. Plasma total cholesterol and TAG levels were determined by enzymatic techniques ${ }^{(35,36)}$. HDL cholesterol was determined after precipitation with phosphowolframic $\operatorname{acid}^{(37)}$. ApoA-I and ApoB were determined by immunoturbidimetry ${ }^{(38)}$. LDL-cholesterol concentration was calculated using the Friedewald formula ${ }^{(39)}$. Plasma ApoE concentration was measured using an immunonephelometric method on a BN ProSpec System with commercial kits (Dade Behring, Deerfield, IL, USA).

\section{DNA amplification and genotyping of ApoE}

Amplification of a region of $266 \mathrm{bp}$ of the apoE genotype was done by PCR with $250 \mathrm{ng}$ of genomic DNA, $0 \cdot 2 \mu \mathrm{mol}$ of each oligonucleotide primer (E1 5'-GAACAACTGACCCCGGTGGCGGAG-3' and E2 5'-TCGCGGGCCCCGGCCTGGTACACTGCCA- $3^{\prime}$ ) and $10 \%$ dimethyl sulfoxide in $50 \mu$ l. DNA was denatured at $95^{\circ} \mathrm{C}$ for $5 \mathrm{~min}$ followed by thirty cycles of denaturation at $95^{\circ} \mathrm{C}$ for $1 \mathrm{~min}$, annealing at $63^{\circ} \mathrm{C}$ for $1.5 \mathrm{~min}$ and extension at $72^{\circ} \mathrm{C}$ for $2 \mathrm{~min}$. Twenty microlitres of the PCR product were digested with ten units of restriction enzyme CfoI (BRL, Gaithersburg, MD, USA) in a total volume of $35 \mu l$. Digested DNA was separated by electrophoresis on an $8 \%$ non-denaturing polyacrylamide gel at $150 \mathrm{~V}$ for $2 \mathrm{~h}$. Bands were visualised by silver staining.

\section{Statistical analysis}

We used the repeated-measures ANOVA to test the effects of the apoE gene polymorphism or sex on plasma total cholesterol, LDL-cholesterol, HDL-cholesterol, TAG, ApoA-I, ApoB and ApoE concentrations after each dietary stage. When statistical significance was found, Tukey's post hoc comparison test was used to identify group differences. TAG and ApoE plasma levels were log-transformed before statistical analyses. Independent sample $t$ test was conducted between the two groups that consumed the MUFA, then the $\mathrm{CHO} v$. the $\mathrm{CHO}$ and then the MUFA diet to test whether the MUFA-CHO differences depended on whether MUFA or $\mathrm{CHO}$ was first (order effects). Statistical significance was considered at $P<0 \cdot 05$. Statistical analyses were conducted using the SPSS statistical software, version 9.0 (SPSS Inc., Chicago, IL, USA). 


\section{Results}

Significant differences were observed when we compared the baseline characteristics of subjects with sex (Table 1). Women had significantly lower BMI and TAG and higher HDL-C and ApoA-I plasma levels than men. Table 2 shows age, BMI and plasma lipid and apoE levels by $a p o E$ genotype and sex at the beginning of the study. Mean total and LDL-cholesterol levels were significantly $(P<0.05)$ higher in subjects with the apoE4/3 genotype when compared with apoE3/3 and apoE $3 / 2$ individuals in both men and women. Furthermore, we observed that the ApoE plasma concentration differed significantly $(P<0 \cdot 05)$ among apoE genotypes in both sexes: apoE2 carriers had the highest ApoE plasma concentrations and subjects with the apoE4 allele had the lowest.

The composition of the mean daily intake of the participants is shown in Table 3. Analysis of fatty acid composition of LDL-cholesterol esters obtained after each dietary period showed good adherence in the different intervention stages. After the SFA diet period, we observed a significantly greater $(P<0.005)$ increase in palmitic acid in the LDL-cholesterol esters than observed after the CHO and MUFA diets: 27.3 (SD 1.4) \% compared with 19.8 (SD 3.9) $\%$ and 15.2 (SD 0.4) $\%$, respectively. A significantly greater $(P<0.05)$ increase in oleic acid in the cholesterol esters was also seen after the MUFA diet (50.3 (SD 4.7) \%) than after the CHO diet (38.8 (SD 9.0) \%), but not after the SFA diet (47.2 (SD 4.4) \%).

Changes in the diet were associated with significant lower concentration of total $(P<0.001)$, LDL $(P<0.001)$ and HDL cholesterol $(P<0.05), \quad$ apoA-I $\quad(P<0.05)$ and apoB $(P<0.001)$ after the CHO and MUFA diets (Table 4). However, in comparison with the MUFA diet, the CHO diet was associated with significant lower plasma concentrations of HDL-C $(P<0.05)$ and apoA-I $(P<0.01)$. Significant differences were not observed in TAG concentrations after the different diets $(P=0.695)$.

Dietary intervention had significant effects on the ApoE plasma concentration (Table 5). In comparison with the SFA diet, the $\mathrm{CHO}$ and MUFA diets were associated with a decrease in the ApoE plasma concentration $(-1.07, P<0.05$ and $-2.47 \mathrm{mg} / \mathrm{l}, P<0.001$, respectively). These differences among diets were observed in women, but not in men (Table 5). However, when the CHO diet was compared with the MUFA diet, no significant differences were observed for ApoE plasma

Table 1. Baseline characteristics of plasma lipids and apo according to sex before the dietary intervention study *

(Mean values and standard deviations)

\begin{tabular}{|c|c|c|c|c|c|}
\hline & \multicolumn{2}{|c|}{ Men $(n 56)$} & \multicolumn{2}{|c|}{ Women (n 28) } & \multirow[b]{2}{*}{$P$} \\
\hline & Mean & SD & Mean & SD & \\
\hline Age (years) & 21.38 & 1.36 & 22.36 & 1.07 & 0.18 \\
\hline $\mathrm{BMI}\left(\mathrm{kg} / \mathrm{m}^{2}\right)$ & 23.00 & $2 \cdot 76$ & $20 \cdot 04$ & 2.54 & 0.001 \\
\hline Total C $(\mathrm{mmol} / \mathrm{l})$ & $4 \cdot 10$ & 0.59 & $4 \cdot 16$ & 0.67 & 0.81 \\
\hline LDL-C $(\mathrm{mmol} / \mathrm{l})$ & $2 \cdot 50$ & 0.59 & $2 \cdot 37$ & 0.66 & 0.40 \\
\hline HDL-C (mmol/l) & $1 \cdot 18$ & 0.35 & 1.48 & 0.39 & 0.001 \\
\hline ApoA-I (g/l) & 1.24 & 0.15 & 1.57 & 0.16 & 0.001 \\
\hline Aров $(g / l)$ & 0.64 & 0.13 & 0.72 & 0.12 & 0.16 \\
\hline ApoE (mg/l) & 32.83 & 0.96 & 34.7 & 1.41 & 0.24 \\
\hline TAG $(\mathrm{mmol} / \mathrm{l})$ & 0.92 & 0.46 & 0.66 & 0.27 & 0.006 \\
\hline
\end{tabular}

* Data were analysed by ANOVA.
Table 2. Baseline characteristics of plasma lipids and apo by apoE genotypes and sex *

(Mean values and standard deviations)

\begin{tabular}{|c|c|c|c|c|c|c|c|}
\hline & \multicolumn{2}{|c|}{ ApoE4/3 } & \multicolumn{2}{|c|}{ ApoE3/3 } & \multicolumn{2}{|c|}{ ApoE3/2 } & \multirow[b]{2}{*}{$P$} \\
\hline & Mean & SD & Mean & SD & Mean & SD & \\
\hline \multicolumn{8}{|l|}{ Age (years) } \\
\hline Men & 23.33 & 2.51 & 21.23 & 1.85 & 21.25 & 2.60 & 0.22 \\
\hline Women & 23.01 & 1.54 & $22 \cdot 25$ & 1.05 & 21.00 & 1.78 & 0.26 \\
\hline \multicolumn{8}{|c|}{ BMI $\left(\mathrm{kg} / \mathrm{m}^{2}\right)$} \\
\hline Men & $22 \cdot 84$ & 2.43 & 23.83 & $2 \cdot 70$ & 24.29 & 2.79 & 0.72 \\
\hline Women & 21.76 & 3.29 & $19 \cdot 70$ & $2 \cdot 64$ & $17 \cdot 34$ & 3.18 & $0 \cdot 18$ \\
\hline \multicolumn{8}{|c|}{ Total C (mmol/l) } \\
\hline Men & $4.89^{a}$ & 0.41 & $4.07^{\mathrm{b}}$ & 0.64 & $3.74^{\mathrm{b}}$ & 0.55 & 0.028 \\
\hline Women & $4.53^{\mathrm{a}}$ & 0.50 & $4 \cdot 11^{\mathrm{b}}$ & 0.52 & $3 \cdot 81^{\mathrm{b}}$ & 0.10 & 0.036 \\
\hline \multicolumn{8}{|c|}{ LDL-C $(\mathrm{mmol} / \mathrm{l})$} \\
\hline Men & $3 \cdot 20^{a}$ & 0.38 & $2 \cdot 48^{\mathrm{b}}$ & 0.59 & $2 \cdot 10^{\mathrm{b}}$ & 0.51 & 0.021 \\
\hline Women & $2 \cdot 84^{a}$ & 0.48 & $2 \cdot 31^{b}$ & 0.62 & $2 \cdot 01^{\mathrm{b}}$ & 0.39 & 0.043 \\
\hline \multicolumn{8}{|c|}{ HDL-C (mmol/l) } \\
\hline Men & 1.28 & 0.27 & $1 \cdot 19$ & 0.29 & $1 \cdot 10$ & 0.22 & 0.59 \\
\hline Women & 1.43 & 0.43 & 1.48 & 0.40 & 1.52 & 0.61 & 0.96 \\
\hline \multicolumn{8}{|l|}{ ApoA-I (g/l) } \\
\hline Men & 1.26 & 0.29 & 1.23 & 0.22 & $1 \cdot 19$ & 0.20 & 0.84 \\
\hline Women & 1.60 & 0.15 & 1.53 & 0.13 & 1.63 & 0.11 & 0.41 \\
\hline \multicolumn{8}{|l|}{ ApoB (g/l) } \\
\hline Men & 0.77 & 0.08 & 0.64 & 0.15 & 0.57 & 0.12 & 0.09 \\
\hline Women & 0.82 & 0.13 & 0.72 & 0.12 & 0.67 & 0.04 & 0.25 \\
\hline \multicolumn{8}{|l|}{ ApoE $(\mathrm{mg} / \mathrm{l})$} \\
\hline Men & $23 \cdot 21^{a}$ & 2.56 & $30 \cdot 81^{b}$ & 1.98 & $43.63^{c}$ & $2 \cdot 31$ & 0.023 \\
\hline Women & $27 \cdot 34^{\mathrm{a}}$ & $2 \cdot 28$ & $32 \cdot 27^{b}$ & 2.25 & $46 \cdot 53^{c}$ & 3.14 & 0.034 \\
\hline \multicolumn{8}{|c|}{$\mathrm{TAG}(\mathrm{mmol} / \mathrm{l})$} \\
\hline Men & 0.91 & 0.12 & 0.88 & 0.49 & 1.14 & 0.39 & 0.30 \\
\hline Women & 0.56 & 0.20 & 0.67 & 0.27 & 0.63 & 0.24 & 0.75 \\
\hline
\end{tabular}

$\overline{a, b, c}$ Mean values within a row with unlike superscript letters were significantly different between genotypes $(P<0.05$; ANOVA).

${ }^{*} A$ group of eighty-four subjects (eight apoE4/3, sixty-six apoE3/3, ten apoE3/2), including men ( $n 56$; four apoE4/3, forty-six apoE3/3 and six apoE3/2) and women ( $n$ 28; four apoE4/3, twenty apoE3/3 and four apoE3/2).

levels in either men or women. In addition, a significant effect on the ApoE concentration was observed for the interaction between diet and sex. Thus, women had significantly higher ApoE plasma levels than men after the SFA diet $(P=0.003)$, but not after the MUFA or CHO diet (Table 5).

The apoE genotype determined the ApoE plasma concentration $(P<0 \cdot 001)$, which was lower in subjects with the apoE4/3 genotype (25.63 (SD 2.22) $\mathrm{mg} / \mathrm{l})$, intermediate in apoE3/3 subjects (31.02 (SD 0.68$) \mathrm{mg} / \mathrm{l})$ and higher in apoE3/2 individuals (44.42 (SD 1.82) $\mathrm{mg} / \mathrm{l})$ after the SFA, CHO and MUFA diet periods. These differences among $a p o E$ genotypes were observed for both men and women (data not shown). On the other hand, a significant $\operatorname{sex} \times \operatorname{diet} \times$ genotype interaction effect was found for the ApoE plasma concentration $(P<0 \cdot 05)$. In women, but not in men, the shift from the SFA diet to the MUFA diet significantly decreased $(P<0.05)$ the ApoE plasma concentration in apoE3/3 $(-8.12 \%)$ and apoE3/2 $(-11.92 \%)$ subjects, whereas apoE4/3 individuals maintained with almost similar levels of $\operatorname{ApoE}(-3.07 \%)$. Additionally, there was a significant decrease in the ApoE plasma concentration in women with the apoE3/3 and apoE3/2 genotypes after changing from a SFA to a CHO diet $(-4.67$ and $-9.71 \%$, respectively, $P<0.05)$, whereas no differences $(1.65 \%)$ were observed in women with the apoE4/3 genotype (Table 6). Finally, women with the apoE3/3 and apoE3/2 genotypes showed 
Table 3. Daily intake during each experimental diet period

\begin{tabular}{|c|c|c|c|}
\hline & SFA diet & $\mathrm{CHO}$ diet & MUFA diet \\
\hline \multicolumn{4}{|c|}{ Protein (percentage of energy intake) } \\
\hline Calculated & 15 & 15 & 15 \\
\hline Analysed & $18 \cdot 0$ & 17.5 & $17 \cdot 7$ \\
\hline \multicolumn{4}{|c|}{ Fat (percentage of energy intake) } \\
\hline \multicolumn{4}{|l|}{ Saturated } \\
\hline Calculated & 20 & 10 & 10 \\
\hline Analysed & $22 \cdot 2$ & $9 \cdot 1$ & $9 \cdot 1$ \\
\hline \multicolumn{4}{|c|}{ Monounsaturated } \\
\hline Calculated & 12 & 12 & 22 \\
\hline Analysed & $11 \cdot 1$ & $13 \cdot 2$ & $24 \cdot 1$ \\
\hline \multicolumn{4}{|c|}{ Polyunsaturated } \\
\hline Calculated & 6 & 6 & 6 \\
\hline Analysed & $5 \cdot 1$ & $5 \cdot 2$ & 4.9 \\
\hline \multicolumn{4}{|c|}{ Carbohydrates (percentage of energy intake) } \\
\hline Calculated & 47 & 57 & 47 \\
\hline Analysed & $44 \cdot 2$ & 54.5 & $44 \cdot 1$ \\
\hline Complex & $27 \cdot 1$ & $33 \cdot 3$ & 27.5 \\
\hline Simple & $17 \cdot 1$ & $21 \cdot 2$ & $16 \cdot 6$ \\
\hline \multicolumn{4}{|c|}{ Cholesterol $(\mathrm{mg} / \mathrm{d})$} \\
\hline Calculated & 285 & 285 & 285 \\
\hline Analysed & 272 & 275 & 277 \\
\hline \multicolumn{4}{|l|}{ Fibre $(g / d)$} \\
\hline Calculated & 30 & 30 & 30 \\
\hline Analysed & $25 \cdot 8$ & $26 \cdot 0$ & $24 \cdot 6$ \\
\hline Energy (MJ) & $10 \cdot 2$ & $10 \cdot 2$ & $10 \cdot 2$ \\
\hline
\end{tabular}

$\mathrm{CHO}$, low-fat, high-carbohydrate diet.

higher ApoE plasma levels than men after the SFA-rich diet, but not after the MUFA or CHO diet (Table 6). No significant differences between men and women were observed in apoE4/3 subjects after the three dietary periods.

Plasma lipids were analysed in both men and women according to the apoE genotype at the end of each diary stage (Tables 7 and 8). Significant differences in the HDL-cholesterol $(P=0.016)$ and TAG $(P=0.030)$ levels were observed between women with the apoE3/2 genotype and those with the apoE3/3 and apoE4/3 genotypes when changing their diet from SFA to MUFA or $\mathrm{CHO}$ (Table 8). In women with the apoE3/2 genotype, the decrease in the HDL-cholesterol plasma concentration was significantly greater than that in women with the apoE3/3 or apoE4/3 genotype when these women switched from a SFA diet to a CHO or MUFA diet (apoE3/2 - 16 and $-13 \% v$.

Table 4. Plasma lipid levels of all subjects ( $n$ 84) after dietary intervention (Mean values and standard deviations)

\begin{tabular}{|c|c|c|c|c|c|c|}
\hline & \multicolumn{2}{|c|}{ SFA } & \multicolumn{2}{|c|}{$\mathrm{CHO}$} & \multicolumn{2}{|c|}{ MUFA } \\
\hline & Mean & SD & Mean & SD & Mean & SD \\
\hline $\begin{array}{l}\text { Total cholesterol } \\
(\mathrm{mmol} / \mathrm{l})\end{array}$ & $4 \cdot 24^{\mathrm{a}}$ & 0.62 & $3 \cdot 68^{b}$ & 0.60 & $3.75^{\mathrm{b}}$ & 0.64 \\
\hline LDL-C (mmol/l) & $2 \cdot 61^{a}$ & 0.60 & $2 \cdot 17^{b}$ & 0.56 & $2 \cdot 20^{\mathrm{b}}$ & 0.60 \\
\hline $\mathrm{HDL}-\mathrm{C}(\mathrm{mmol} / \mathrm{l})$ & $1.23^{\mathrm{a}}$ & 0.29 & $1 \cdot 12^{\mathrm{b}}$ & 0.25 & $1 \cdot 18^{\mathrm{C}}$ & 0.29 \\
\hline ApoA-I (g/l) & $1.35^{\mathrm{a}}$ & 0.24 & $1 \cdot 25^{\mathrm{b}}$ & 0.22 & $1 \cdot 29^{c}$ & 0.24 \\
\hline ApoB $(g / l)$ & $0.68^{a}$ & 0.15 & $0.59^{b}$ & 0.15 & $0.60^{\mathrm{b}}$ & 0.15 \\
\hline TAG (mmol/l) & 0.82 & 0.37 & 0.82 & 0.35 & 0.79 & 0.31 \\
\hline
\end{tabular}

C, cholesterol.

${ }^{a, b, c}$ Mean values within a row with unlike superscript letters were significantly different between genotypes ( $P<0.001$; repeated-measures ANOVA).
apoE3/3 -8 and $-7 \%$ and apoE4/3 -4 and $-1 \%$, respectively). In addition, women with the apoE3/2 genotype had an increase in TAG concentrations after changing their diet from SFA to CHO or MUFA, whereas women with the apoE3/3 or apoE4/3 genotype maintained with almost similar levels (apoE3/2 14 and $16 \%$ v. apoE3/3 3 and $7 \%$ and apoE4/3 -4 and $-1 \%$, respectively). These differences in the HDLcholesterol or TAG levels were not observed for men.

\section{Discussion}

The present results show that sex and apoE genotype determine ApoE plasma levels; however, this effect is dependent on dietary fat. Thus, women had significantly higher ApoE concentration than men only after the consumption of the SFA diet. Furthermore, we have observed that women with the apoE3/2 and apoE3/3 genotypes have a greater increase in the ApoE plasma levels when a SFA-rich diet is consumed instead of a CHO- or MUFA-rich diet.

The importance of the $a p o E$ polymorphism on lipid metabolism and CHD is well known. Several matched case-control studies have shown a modest but significantly increased prevalence of the apoE4 allele in CHD patients from various populations $^{(40,41)}$. Nevertheless, even though the apoE4 allele appears to be a significant genetic risk factor for CHD, individuals with the apoE4 allele do not inevitably develop this disorder. It has been recently proposed that together with the qualitative modification of the ApoE structure due to the apoE alleles, quantitative variations in the ApoE plasma levels could play a major role in determining risk ${ }^{(6-9,42)}$. In agreement with this hypothesis, it has been observed that ApoE concentration determines serum lipid levels by modulating lipoprotein production, lipolytic conversion and receptor-mediated clearance, independently of the ApoE polymorphism ${ }^{(43)}$. Furthermore, circulating ApoE concentration appears to be altered in hyperlipidaemic human and animal subjects ${ }^{(1-13,27)}$, and several case-control studies show that ApoE plasma levels, per se, may be a risk factor for $\mathrm{CHD}^{(14-17)}$.

A wide total interindividual variation in the ApoE plasma concentration has been observed in previous reports, which has been principally attributed to the $a p o E$ common polymorphism ${ }^{(20,21)}$. In accordance with the present results, previous studies have shown that apoE2 carriers have the highest levels, whereas apoE4 individuals show the lowest concentration $^{(20,21)}$. However, a large amount of variability $(65-75 \%)$ remains unexplained by this genetic factor, suggesting that other variables could be involved in determining the ApoE concentration. In several tissues, apoE expression is up-regulated by oestrogens ${ }^{(44)}$, so sex was proposed to be one of these variables. However, the data available to date are contradictory: whereas some studies found that ApoE levels are higher in women when compared with men $^{(26-28)}$, others reported the opposite relationship ${ }^{(29)}$ or no differences ${ }^{(30)}$. These inconsistencies may be explained by the variety of methods used for ApoE measurements, different ages of the subjects or environmental factors, such as $\operatorname{diet}^{(45,46)}$. We suggest this latter one as a source of variability due to an increasing male to female gradient in the serum ApoE concentration when the subjects consumed a SFA-rich diet. It has been demonstrated that a SFA-rich diet leads to elevations in the ApoE plasma levels ${ }^{(23,24)}$, but different 
Table 5. ApoE plasma concentration ( $\mathrm{mg} / \mathrm{l})$ by sex at the end of each dietary period (Mean values and standard deviations)

\begin{tabular}{|c|c|c|c|c|c|c|c|}
\hline & \multicolumn{2}{|c|}{ SFA } & \multicolumn{2}{|c|}{$\mathrm{CHO}$} & \multicolumn{2}{|c|}{ MUFA } & \multirow[b]{2}{*}{$P$} \\
\hline & Mean & SD & Mean & SD & Mean & SD & \\
\hline Total $(n$ 84) & $34.61^{a}$ & 4.87 & $33.54^{b}$ & 3.97 & $32 \cdot 14^{b}$ & 4.96 & 0.008 \\
\hline Men $(n 56)$ & $33.01^{c}$ & $7 \cdot 82$ & $32 \cdot 86$ & 8.98 & 31.43 & $8 \cdot 20$ & 0.15 \\
\hline Women (n 28) & $36 \cdot 21^{a, d}$ & 6.54 & $34 \cdot 22^{b}$ & 6.83 & $32 \cdot 86^{\mathrm{b}}$ & 8.35 & 0.009 \\
\hline
\end{tabular}

responses between men and women were not previously analysed. The present results suggest the existence of a SFA-oestrogen interaction that could increase the ApoE levels in women. Thus, oestrogens may enhance the SFA-raising effect, resulting in a higher difference on the ApoE plasma levels between sexes, as we have observed. These results require confirmation in future studies since experimental data to corroborate this hypothesis do not exist.

To our knowledge, this is the first intervention study comparing the effect of both the quantity and quality of dietary fat on the ApoE concentration. In spite of a small sample size, we found that a SFA-rich diet increases the ApoE plasma levels in comparison with a CHO- and MUFA-rich diet, a counter-intuitive finding, in view of the healthful properties of ApoE. Metabolically, ApoE interacts with different receptors in the liver, inducing the uptake of TAG-rich particles from the circulation ${ }^{(3)}$. Thus, we would expect that ApoE plasma levels would be a protective influence

Table 6. ApoE plasma concentration (mg/l) in subjects with different apoE genotypes and sexes at the end of each dietary intervention period *

(Mean values and standard deviations)

\begin{tabular}{|c|c|c|c|c|}
\hline \multirow[b]{2}{*}{ Genotype-diet } & \multicolumn{2}{|c|}{ Men ( $n$ 56) } & \multicolumn{2}{|c|}{ Women (n 28) } \\
\hline & Mean & SD & Mean & SD \\
\hline \multicolumn{5}{|l|}{ apoE4/3 (n 8) } \\
\hline SFA & $24 \cdot 71$ & 1.55 & $26 \cdot 63$ & 1.86 \\
\hline $\mathrm{CHO}$ & $25 \cdot 13$ & 2.96 & $27 \cdot 07$ & 3.64 \\
\hline MUFA & $23 \cdot 12$ & 1.17 & $25 \cdot 81$ & 2.47 \\
\hline \multicolumn{5}{|l|}{ apoE3/3 (n 66) } \\
\hline SFA & $30 \cdot 43^{c}$ & 5.76 & $34 \cdot 22^{\mathrm{a}, \mathrm{d}}$ & $5 \cdot 34$ \\
\hline $\mathrm{CHO}$ & 29.62 & $7 \cdot 14$ & $32 \cdot 62^{\mathrm{b}}$ & 4.77 \\
\hline MUFA & $29 \cdot 33$ & $6 \cdot 84$ & $31.44^{\mathrm{b}}$ & 7.74 \\
\hline \multicolumn{5}{|l|}{ apoE3/2 (n 10) } \\
\hline SFA & $43 \cdot 61^{\mathrm{c}}$ & $5 \cdot 87$ & $48 \cdot 40^{\mathrm{a}, \mathrm{d}}$ & 5.79 \\
\hline $\mathrm{CHO}$ & $43 \cdot 13$ & $7 \cdot 24$ & $43 \cdot 70^{b}$ & $6 \cdot 76$ \\
\hline MUFA & 41.68 & $5 \cdot 69$ & $42 \cdot 65^{b}$ & 3.65 \\
\hline \multicolumn{5}{|l|}{$P$} \\
\hline Diet & \multicolumn{2}{|c|}{0.128} & \multicolumn{2}{|c|}{0.041} \\
\hline Genotype & \multicolumn{2}{|c|}{0.001} & \multicolumn{2}{|c|}{0.001} \\
\hline Interaction & \multicolumn{2}{|c|}{0.215} & \multicolumn{2}{|c|}{0.012} \\
\hline
\end{tabular}

${ }^{a, b, c}$ Mean values within a row with unlike superscript letters were significantly different between diet groups for a given genotype $(P<0.05)$.

${ }^{\mathrm{c}, \mathrm{d}}$ Mean values within a row with unlike superscript letters were significantly different between men and women for a given diet period $(P<0.05)$.

* Men (four apoE4/3, forty-six apoE3/3 and six apoE3/2) and women (four apoE4/3, twenty apoE3/3 and four apoE3/2). against CHD. Surprisingly, ApoE levels are increased in patients with $\mathrm{CHD}^{(17,19,47-49)}$ and non-insulin-dependent diabetes $^{(50,51)}$. These observations illustrate the fact that an elevation in the ApoE plasma concentration increases cardiovascular risk and could explain why the SFA-rich diets, which have been associated with dyslipidaemia and a higher cardiovascular risk, are associated with a higher ApoE plasma concentration. The mechanisms behind this association are unclear. It has been observed that ApoE may be beneficial up to a point, but a further increase may then lead to alterations in lipid metabolism ${ }^{(7)}$. Accordingly, the increase in the ApoE expression of human apoE in transgenic mice stimulates VLDL production by the liver and inhibits VLDL lipolysis by lipoprotein lipase ${ }^{(52)}$. In addition, increased levels of ApoE might render the excess ApoE unavailable for receptor interaction, resulting in the inhibition of remnant clearance ${ }^{(53)}$. Therefore, it is necessary to highlight that an optimal ApoE plasma concentration is necessary to maintain lipid homeostasis. It is not well understood how SFA increases the ApoE plasma levels; however, it was proposed that this effect could be related to a post-transcriptional mechanism, possibly decreasing both receptor-mediated uptake and hydrolysis of ApoE-containing particles ${ }^{(54)}$. In agreement with this hypothesis, a greater enrichment of TAG-rich lipoproteins with apoE and C-III has been observed after the consumption of meals rich in $\mathrm{SFA}^{(55)}$.

When we take into account the influence of the apoE genotype on this complex sex-diet interaction, we observed that the ApoE-raising effect of the SFA diets was only observed in women with the apoE3/2 and apoE3/3 genotypes, but not in men. Carriers of the E2 allele had higher mean apoE-HDL concentrations and lower apoE-VLDL concentrations than individuals carrying the E3 allele, whereas subjects with the E4 allele showed the inverse profile ${ }^{(56)}$. This fact is in accordance with the known preference of apoE4 for apoB-containing lipoproteins and the preferential association of the apoE2 isoform with HDL particles. Furthermore, it has been reported that women, compared with men, have more ApoE in lipoproteins than in VLDL, mainly HDL particles ${ }^{(26)}$. Therefore, it is logical that the SFA-raising effect associated with women could be higher in those carriers of the apoE2 allele, as we have observed, since ApoE is mainly associated with HDL particles in women with this genotype. In agreement with this hypothesis, a higher response for the HDLcholesterol plasma concentration was observed in women with the apoE3/2 genotype after changing their diet from SFA to CHO or MUFA. However, the mechanism of how 
Table 7. Plasma lipids ( $\mathrm{mmol} / \mathrm{l})$ and apo $(\mathrm{g} / \mathrm{l})$ in men at the end of each dietary period according to the apoE genotype (Mean values and standard deviations)

\begin{tabular}{|c|c|c|c|c|c|c|c|c|c|c|c|c|}
\hline & \multicolumn{2}{|c|}{ Total C } & \multicolumn{2}{|c|}{ LDL-C } & \multicolumn{2}{|c|}{ HDL-C } & \multicolumn{2}{|c|}{ ApoA-I } & \multicolumn{2}{|c|}{ ApoB } & \multicolumn{2}{|c|}{ TAG } \\
\hline & Mean & SD & Mean & SD & Mean & SD & Mean & SD & Mean & SD & Mean & SD \\
\hline \multicolumn{13}{|l|}{ apoE4/3 (n 4) } \\
\hline SFA & $4 \cdot 67^{\mathrm{a}}$ & 0.44 & $3.03^{a}$ & 0.28 & 1.25 & 0.20 & 1.29 & 0.23 & $0.79^{\mathrm{a}}$ & 0.09 & 0.83 & 0.28 \\
\hline $\mathrm{CHO}$ & $4 \cdot 22^{\mathrm{a}}$ & 0.35 & $2 \cdot 71^{\mathrm{a}}$ & 0.27 & $1 \cdot 10$ & 0.11 & $1 \cdot 12$ & 0.14 & $0.71^{\mathrm{a}}$ & 0.17 & 0.82 & 0.10 \\
\hline MUFA & $4 \cdot 15^{a}$ & 0.59 & $2 \cdot 42^{\mathrm{a}}$ & 0.58 & $1 \cdot 17$ & 0.13 & $1 \cdot 11$ & 0.18 & $0.73^{a}$ & 0.17 & 0.77 & 0.12 \\
\hline \multicolumn{13}{|l|}{ apoE3/3 (n 46) } \\
\hline SFA & $4 \cdot 21^{b}$ & 0.63 & $2 \cdot 61^{\mathrm{b}}$ & 0.60 & $1 \cdot 17$ & 0.29 & 1.24 & 0.20 & $0.65^{\mathrm{b}}$ & 0.15 & 0.91 & 0.41 \\
\hline $\mathrm{CHO}$ & $3 \cdot 61^{\mathrm{b}}$ & 0.59 & $2 \cdot 20^{\mathrm{b}}$ & 0.53 & 1.09 & 0.24 & $1 \cdot 16$ & 0.19 & $0.56^{\mathrm{b}}$ & 0.14 & 0.86 & 0.38 \\
\hline MUFA & $3.76^{\mathrm{b}}$ & 0.58 & $2 \cdot 22^{\mathrm{b}}$ & 0.54 & $1 \cdot 14$ & 0.28 & 1.20 & 0.20 & $0.57^{\mathrm{b}}$ & 0.14 & 0.83 & 0.29 \\
\hline \multicolumn{13}{|l|}{ apoE3/2 $(n 6)$} \\
\hline SFA & $3.91^{c}$ & 0.39 & $2 \cdot 35^{\mathrm{c}}$ & 0.44 & $1 \cdot 10$ & 0.16 & 1.24 & 0.14 & $0.56^{c}$ & 0.12 & 0.95 & 0.31 \\
\hline $\mathrm{CHO}$ & $3.29^{c}$ & 0.29 & $1.77^{\mathrm{C}}$ & 0.25 & 1.00 & 0.14 & 1.23 & 0.27 & $0.47^{c}$ & 0.12 & 1.08 & 0.38 \\
\hline MUFA & $3.40^{\mathrm{C}}$ & 0.58 & $1.90^{\mathrm{C}}$ & 0.47 & 1.07 & 0.18 & $1 \cdot 19$ & 0.20 & $0.50^{c}$ & 0.16 & 0.90 & 0.38 \\
\hline \multicolumn{13}{|l|}{$P$} \\
\hline Diet & \multirow{2}{*}{\multicolumn{2}{|c|}{0.001}} & \multirow{2}{*}{\multicolumn{2}{|c|}{0.001}} & \multicolumn{2}{|c|}{0.025} & \multicolumn{2}{|c|}{0.001} & \multicolumn{2}{|c|}{0.001} & \multicolumn{2}{|c|}{0.492} \\
\hline Genotype & \multirow{2}{*}{\multicolumn{2}{|c|}{$\begin{array}{l}0.039 \\
0.062\end{array}$}} & \multirow{2}{*}{\multicolumn{2}{|c|}{$\begin{array}{l}0.034 \\
0.041\end{array}$}} & \multirow{2}{*}{\multicolumn{2}{|c|}{0.651}} & \multirow{2}{*}{\multicolumn{2}{|c|}{$\begin{array}{l}0.760 \\
0.052\end{array}$}} & \multirow{2}{*}{\multicolumn{2}{|c|}{$\begin{array}{l}0.048 \\
0.147\end{array}$}} & \multirow{2}{*}{\multicolumn{2}{|c|}{$\begin{array}{l}0.595 \\
0.254\end{array}$}} \\
\hline Interaction & & & & & & & & & & & & \\
\hline
\end{tabular}

C, cholesterol

${ }_{a, b, c}$ Mean values within a row with unlike superscript letters were significantly different between genotype groups for a given diet group $(P<0.05$; repeated-measures ANOVA)

apoE expression is regulated by saturated fatty acid in women with the apoE3/3 and apoE3/2 genotypes is not yet known. New studies are needed, therefore, to confirm the present findings in a larger sample size and to characterise the molecular mechanism responsible for this complex interaction. It is important to note that one of the limitations to genetic association studies is the difficulty in corroborating findings observed in populations with different characteristics. We must be cautious therefore when extrapolating the results to a more general population. We included only healthy young normolipaemic individuals in order to avoid the effect of other factors (age, BMI, etc.) on lipid response to the content and quality of dietary fat. Studies conducted with conditions representing impaired metabolism, as in dyslipoproteinaemic patients, will generally be more successful in finding differential effects across apoE genotypes, and such studies may be helpful in clarifying apoE-nutrition relationships.

In conclusion, the present paper deals with the study of the principal factors determining the ApoE plasma levels. The present results show that circulating ApoE concentration is determined by both sex and apoE genotype; however, this effect can be modulated by dietary intervention. Since ApoE plasma levels appear to be altered in CVD, the present results can thus give interesting therapeutic data to give individual specific dietary recommendation.

Table 8. Plasma lipids $(\mathrm{mmol} / \mathrm{l})$ and apo $(\mathrm{g} / \mathrm{l})$ in women at the end of each dietary period according to the apoE genotype

(Mean values and standard deviations)

\begin{tabular}{|c|c|c|c|c|c|c|c|c|c|c|c|c|}
\hline & \multicolumn{2}{|c|}{ Total C } & \multicolumn{2}{|c|}{ LDL-C } & \multicolumn{2}{|c|}{ HDL-C } & \multicolumn{2}{|c|}{ ApoA-I } & \multicolumn{2}{|c|}{ ApoB } & \multicolumn{2}{|c|}{ TAG } \\
\hline & Mean & SD & Mean & SD & Mean & SD & Mean & SD & Mean & SD & Mean & SD \\
\hline \multicolumn{13}{|l|}{ apoE4/3 (n 4) } \\
\hline SFA & $4 \cdot 34^{a}$ & 0.51 & $2 \cdot 81^{a}$ & 0.38 & $1 \cdot 30$ & 0.20 & 1.60 & 0.15 & 0.82 & 0.12 & 0.58 & 0.20 \\
\hline $\mathrm{CHO}$ & $4 \cdot 20^{a}$ & 0.31 & $2 \cdot 64^{a}$ & 0.23 & $1 \cdot 24$ & 0.33 & 1.49 & $0 \cdot 10$ & 0.74 & 0.11 & 0.53 & 0.28 \\
\hline $\begin{array}{c}\text { MUFA } \\
\text { apoE3/3 }(n 20\end{array}$ & $3 \cdot 86^{a}$ & 0.27 & $2 \cdot 32^{\mathrm{a}}$ & 0.38 & $1 \cdot 28$ & 0.27 & 1.52 & 0.09 & 0.73 & 0.08 & 0.54 & 0.17 \\
\hline SFA & $4 \cdot 22^{b}$ & 0.68 & $2.54^{b}$ & 0.65 & $1 \cdot 38$ & 0.27 & 1.53 & 0.13 & $0 \cdot 71$ & 0.12 & 0.61 & 0.17 \\
\hline $\mathrm{CHO}$ & $3.53^{b}$ & 0.62 & $2 \cdot 01^{b}$ & 0.61 & $1 \cdot 26$ & 0.27 & 1.40 & 0.13 & 0.61 & 0.12 & 0.63 & 0.18 \\
\hline MUFA & $3 \cdot 61^{b}$ & 0.70 & $2 \cdot 03^{b}$ & 0.61 & $1 \cdot 28$ & 0.33 & 1.46 & 0.17 & 0.62 & 0.11 & 0.65 & 0.26 \\
\hline \multicolumn{13}{|l|}{ apoE3/2 (n 4) } \\
\hline SFA & $3.99^{c}$ & 0.20 & $2 \cdot 31^{c}$ & $0 \cdot 10$ & $1 \cdot 31$ & 0.42 & $1 \cdot 71$ & 0.10 & 0.67 & 0.11 & 0.76 & 0.26 \\
\hline $\mathrm{CHO}$ & $3 \cdot 30^{c}$ & 0.55 & $1 \cdot 78^{c}$ & 0.11 & $1 \cdot 10$ & 0.56 & 1.44 & 0.13 & 0.64 & 0.09 & 0.87 & 0.19 \\
\hline MUFA & $3.52^{c}$ & 0.05 & $1 \cdot 88^{c}$ & 0.43 & $1 \cdot 12$ & 0.55 & $1 \cdot 31$ & 0.12 & 0.61 & 0.09 & 0.88 & 0.19 \\
\hline \multicolumn{13}{|l|}{$P$} \\
\hline Diet & \multicolumn{2}{|c|}{0.001} & \multicolumn{2}{|c|}{0.001} & \multicolumn{2}{|c|}{0.002} & \multicolumn{2}{|c|}{0.001} & \multicolumn{2}{|c|}{0.001} & \multicolumn{2}{|c|}{0.011} \\
\hline Genotype & \multicolumn{2}{|c|}{0.019} & \multicolumn{2}{|c|}{0.043} & \multicolumn{2}{|c|}{0.959} & \multicolumn{2}{|c|}{0.283} & \multicolumn{2}{|c|}{0.107} & \multicolumn{2}{|c|}{0.335} \\
\hline Interaction & \multicolumn{2}{|c|}{0.014} & \multicolumn{2}{|c|}{0.010} & \multicolumn{2}{|c|}{0.016} & \multicolumn{2}{|c|}{0.054} & \multicolumn{2}{|c|}{0.105} & \multicolumn{2}{|c|}{0.030} \\
\hline
\end{tabular}

C, cholesterol

a,b,c Mean values within a row with unlike superscript letters were significantly different between genotype groups for a given diet group ( $P<0.05$; repeated-measures ANOVA). 


\section{Acknowledgements}

J. A. M. was responsible for the collection and analysis of the data and writing of the manuscript. C. M. and D. L. contributed to the collection of the data. P. P.-M. provided statistical advice and contributed to the writing of the manuscript. R. M. contributed to the collection of the data and the writing of the manuscript. F. F.-J. was responsible for the design of the study and analysis of the data. F. P.-J. and J. L.-M. were responsible for the conception and design of the study, analysis of the data and the writing of the manuscript. None of the authors had any conflict of interest. The present work was supported by Grant Nos SAF 01/0366 and SAF 01/ 2466-C05-04 and SAF2003-05 770 from the Comisión Interministerial de Ciencia y Tecnología; Grant No. FIS 01/0449 from the Spanish Ministry of Health and CB0/6/03 from the Instituto de Salud Carlos III; grants from the Fundación Cultural Hospital Reina Sofía-Cajasur, Consejería de Educación and Consejería de Salud from Junta de Andalucía, 01/243, 02/65, 03/75, 04/238, 02/77, 03/73, 04/191, 04/237, 02/64 and from Diputación Provincial de Córdoba.

\section{References}

1. Beisiegel U, Weber W, Ihrke G, et al. (1989) The LDL-receptor-related protein, LRP, is an apolipoprotein E-binding protein. Nature 341, 162-164.

2. Weisgraber KH (1994) Apolipoprotein E: structure-function relationships. Adv Protein Chem 45, 249-302.

3. Miettinen TA, Gylling H, Vanhanen H, et al. (1992) Cholesterol absorption, elimination, and synthesis related to LDL kinetics during varying fat intake in men with different apoprotein $\mathrm{E}$ phenotypes. Arterioscler Thromb 12, 1044-1052.

4. Dallongeville J, Lussier-Cacan S \& Davignon J (1992) Modulation of plasma triglyceride levels by apoE phenotype: a meta-analysis. J Lipid Res 33, 447-454.

5. Wilson PW, Myers RH, Larson MG, et al. (1994) Apolipoprotein $\mathrm{E}$ alleles, dyslipidemia, and coronary heart disease. The Framingham Offspring Study. J Am Med Assoc 272, $1666-1671$.

6. Siest G, Pillot T, Regis-Bailly A, et al. (1995) Apolipoprotein E: an important gene and protein to follow in laboratory medicine. Clin Chem 41, 1068-1086.

7. Huang Y, Liu XQ, Rall SC Jr, et al. (1998) Overexpression and accumulation of apolipoprotein $\mathrm{E}$ as a cause of hypertriglyceridemia. J Biol Chem 273, 26388-26393.

8. Gracia V, Fiol C, Hurtado I, et al. (1994) An enzyme-linked immunosorbent assay method to measure human apolipoprotein E levels using commercially available reagents: effect of apolipoprotein E polymorphism on serum apolipoprotein E concentration. Anal Biochem 223, 212-217.

9. Taddei K, Clarnette R, Gandy SE, et al. (1997) Increased plasma apolipoprotein E (apoE) levels in Alzheimer's disease. Neurosci Lett 223, 29-32.

10. Havel RJ \& Kane JP (1973) Primary dysbetalipoproteinemia: predominance of a specific apoprotein species in triglyceriderich lipoproteins. Proc Natl Acad Sci U S A 70, 2015-2019.

11. Curry MD, McConathy WJ, Alaupovic P, et al. (1976) Determination of human apolipoprotein $\mathrm{E}$ by electroimmunoassay. Biochim Biophys Acta 439, 413-425.

12. Kushwaha RS, Hazzard WR, Wahl PW, et al. (1977) Type III hyperlipoproteinemia: diagnosis in whole plasma by apolipoprotein-E immunoassay. Ann Intern Med 87, 509-516.
13. Morrisett JD, Kim HS, Patsch JR, et al. (1982) Genetic susceptibility and resistance to diet-induced atherosclerosis and hyperlipoproteinemia. Arteriosclerosis 2, 312-324.

14. Lambert JC, Brousseau T, Defosse V, et al. (2000) Independent association of an APOE gene promoter polymorphism with increased risk of myocardial infarction and decreased APOE plasma concentrations - the ECTIM study. Hum Mol Genet 9, 57-61.

15. Corbo RM, Vilardo T, Ruggeri M, et al. (1999) Apolipoprotein E genotype and plasma levels in coronary artery disease. A case-control study in the Italian population. Clin Biochem 32, 217-222.

16. Corbo RM, Vilardo T, Mantuano E, et al. (1997) Apolipoproteins $\mathrm{B}$ and $\mathrm{E}$, and angiotensin I-converting enzyme (ACE) genetic polymorphisms in Italian women with coronary artery disease (CAD) and their relationships with plasma lipid and apolipoprotein levels. Clin Genet 52, 77-82.

17. Schwartzkopff W, Schleicher J, Pottins I, et al. (1990) Lipids, lipoproteins, apolipoproteins, and other risk factors in Chinese men and women with and without myocardial infarction. Atherosclerosis 82, 253-259.

18. Lee SJ, Moye LA \& Campos H (2003) Hypertriglyceridemia but not diabetes status is associated with VLDL containing apolipoprotein CIII in patients with coronary heart disease. Atherosclerosis 167, 293-302.

19. Syvanne M, Rosseneu M, Labeur C, et al. (1994) Enrichment with apolipoprotein E characterizes postprandial TG-rich lipoproteins in patients with non-insulin-dependent diabetes mellitus and coronary artery disease: a preliminary report. Atherosclerosis 105, 25-34.

20. Vincent-Viry M, Schiele F, Gueguen R, et al. (1998) Biological variations and genetic reference values for apolipoprotein E serum concentrations: results from the STANISLAS cohort study. Clin Chem 44, 957-965.

21. Neale MC, de Knijff P, Havekes LM, et al. (2000) ApoE polymorphism accounts for only part of the genetic variation in quantitative ApoE levels. Genet Epidemiol 18, 331-340.

22. Patsch W, Gotto AM Jr \& Patsch JR (1986) Effects of insulin on lipoprotein secretion in rat hepatocyte cultures. The role of the insulin receptor. J Biol Chem 261, 9603-9606.

23. Innerarity TL \& Mahley RW (1978) Enhanced binding by cultured human fibroblasts of apo-E-containing lipoproteins as compared with low density lipoproteins. Biochemistry 17, 1440-1447.

24. Mahley RW (1982) Atherogenic hyperlipoproteinemia. The cellular and molecular biology of plasma lipoproteins altered by dietary fat and cholesterol. Med Clin North Am 66, 375-402.

25. Reue KL, Quon DH, O'Donnell KA, et al. (1984) Cloning and regulation of messenger RNA for mouse apolipoprotein E. J Biol Chem 259, 2100-2107.

26. Phillips NR, Havel RJ \& Kane JP (1983) Sex-related differences in the concentrations of apolipoprotein $\mathrm{E}$ in human blood plasma and plasma lipoproteins. J Lipid Res 24, 1525-1531.

27. Havel RJ, Kotite L, Vigne JL, et al. (1980) Radioimmunoassay of human arginine-rich apolipoprotein, apoprotein E. Concentration in blood plasma and lipoproteins as affected by apoprotein E-3 deficiency. J Clin Invest 66, 1351-1362.

28. Noma A, Hata Y \& Goto Y (1991) Quantitation of serum apolipoprotein A-I, A-II, B, C-II, C-III and E in healthy Japanese by turbidimetric immunoassay: reference values, and age- and sex-related differences. Clin Chim Acta 199, 147-157.

29. Rifai N, McMurray RG \& Silverman LM (1987) The effects of the behavioral patterns on lipoprotein profile. Clin Chim Acta 169, 333-335.

30. Au YP, Bren ND \& Kottke BA (1986) A rapid apolipoprotein E radioimmunoassay using solid-phase staphylococcus protein. 
Use of pooled plasma as a secondary standard. Biochem Biophys Res Commun 138, 455-462.

31. Human Nutrition Information Service DoACoF (1987) Agriculture Handbook No. 8. Washington, DC: US Government Printing Office.

32. Varela G (1980) Food Composition Tables (Tablas de composición de alimentos). Madrid: Instituto de Nutrición CSIC.

33. Association of Official Analytical Chemists (1990) Official Methods of Analysis, 15th ed. Aarlington, VA: Association of Official Analytical Chemists.

34. Ruiz-Gutierrez V, Prada JL \& Perez-Jimenez F (1993) Determination of fatty acid and triacylglycerol composition of human very-low-density lipoproteins. J Chromatogr 622, 117-124.

35. Allain CC, Poon LS, Chan CS, et al. (1974) Enzymatic determination of total serum cholesterol. Clin Chem 20, 470-475.

36. Bucolo G \& David H (1973) Quantitative determination of serum triglycerides by the use of enzymes. Clin Chem 19, 476-482.

37. Assmann G, Schriewer H, Schmitz G, et al. (1983) Quantification of high-density-lipoprotein cholesterol by precipitation with phosphotungstic acid/MgCl2. Clin Chem 29, 2026-2030.

38. Riepponen P, Marniemi J \& Rautaoja T (1987) Immunoturbidimetric determination of apolipoproteins A-1 and B in serum. Scand J Clin Lab Invest 47, 739-744.

39. Friedewald WT, Levy RI \& Fredrickson DS (1972) Estimation of the concentration of low-density lipoprotein cholesterol in plasma, without use of the preparative ultracentrifuge. Clin Chem 18, 499-502.

40. Luc G, Bard JM, Arveiler D, et al. (1994) Impact of apolipoprotein $\mathrm{E}$ polymorphism on lipoproteins and risk of myocardial infarction. The ECTIM Study. Arterioscler Thromb 14, $1412-1419$.

41. Nakai K, Fusazaki T, Zhang T, et al. (1998) Polymorphism of the apolipoprotein $\mathrm{E}$ and angiotensin I converting enzyme genes in Japanese patients with myocardial infarction. Coron Artery Dis 9, 329-334.

42. Tiret L, de Knijff P, Menzel HJ, et al. (1994) ApoE polymorphism and predisposition to coronary heart disease in youths of different European populations. The EARS Study. European Atherosclerosis Research Study. Arterioscler Thromb 14, 1617-1624.

43. Bohnet K, Pillot T, Visvikis S, et al. (1996) Apolipoprotein (apo) E genotype and apoE concentration determine binding of normal very low density lipoproteins to HepG2 cell surface receptors. J Lipid Res 37, 1316-1324.

44. Srivastava RA, Srivastava N, Averna M, et al. (1997) Estrogen up-regulates apolipoprotein $\mathrm{E}$ (ApoE) gene expression by increasing ApoE mRNA in the translating pool via the estrogen receptor alpha-mediated pathway. J Biol Chem 272, 33360-33366.
45. Reilly SL, Ferrell RE, Kottke BA, et al. (1992) The genderspecific apolipoprotein E genotype influence on the distribution of plasma lipids and apolipoproteins in the population of Rochester. Minnesota. II. Regression relationships with concomitants. Am J Hum Genet 51, 1311-1324.

46. Schiele F, De Bacquer D, Vincent-Viry M, et al. (2000) Apolipoprotein E serum concentration and polymorphism in six European countries: the ApoEurope Project. Atherosclerosis 152, $475-488$.

47. Johansson S, Bondjers G, Fager G, et al. (1988) Serum lipids and apolipoprotein levels in women with acute myocardial infarction. Arteriosclerosis 8, 742-749.

48. Chivot L, Mainard F, Bigot E, et al. (1990) Logistic discriminant analysis of lipids and apolipoproteins in a population of coronary bypass patients and the significance of apolipoproteins C-III and E. Atherosclerosis 82, 205-211.

49. Sacks FM, Alaupovic P, Moye LA, et al. (2000) VLDL, apolipoproteins B, CIII, and E, and risk of recurrent coronary events in the Cholesterol and Recurrent Events (CARE) trial. Circulation 102, 1886-1892.

50. Fielding CJ, Reaven GM \& Fielding PE (1982) Human noninsulin-dependent diabetes: identification of a defect in plasma cholesterol transport normalized in vivo by insulin and in vitro by selective immunoadsorption of apolipoprotein E. Proc Natl Acad Sci U S A 79, 6365-6369.

51. Weisweiler P \& Schwandt P (1987) Type 1 (insulin-dependent) versus type 2 (non-insulin-dependent) diabetes mellitus: characterization of serum lipoprotein alterations. Eur J Clin Invest 17, 87-91.

52. Huang Y, Liu XQ, Rall SC Jr, et al. (1998) Apolipoprotein E2 reduces the low density lipoprotein level in transgenic mice by impairing lipoprotein lipase-mediated lipolysis of triglyceriderich lipoproteins. J Biol Chem 273, 17483-17490.

53. Rensen PC, Herijgers N, Netscher MH, et al. (1997) Particle size determines the specificity of apolipoprotein E-containing triglyceride-rich emulsions for the LDL receptor versus hepatic remnant receptor in vivo. J Lipid Res 38, 1070-1084.

54. Srivastava RA (1996) Regulation of the apolipoprotein E by dietary lipids occurs by transcriptional and post-transcriptional mechanisms. Mol Cell Biochem 155, 153-162.

55. Jackson KG, Wolstencroft EJ, Bateman PA, et al. (2005) Greater enrichment of triacylglycerol-rich lipoproteins with apolipoproteins E and C-III after meals rich in saturated fatty acids than after meals rich in unsaturated fatty acids. Am J Clin Nutr 81, 25-34.

56. Schiele F, Vincent-Viry M, Starck M, et al. (2002) Apolipoprotein $\mathrm{E}$ in apolipoprotein B (apo B)- and non-apo B-containing lipoproteins in 3523 participants in the Stanislas cohort: biological variation and genotype-specific reference limits. Clin Chem 48, 291-300. 